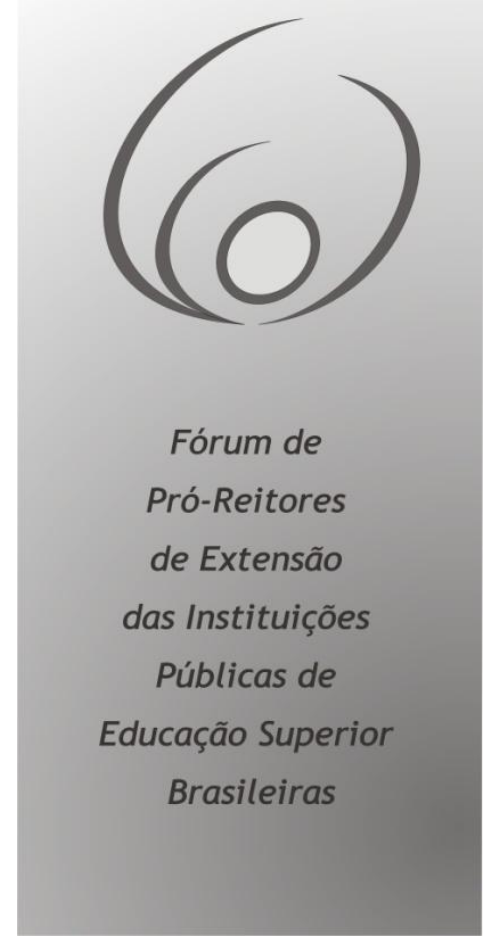

originais recebidos em 07 de maio de 2015

aceito para publicação em 05 de julho de 2015

\title{
Creditação da extensão universitária nos cursos de graduação: relato de experiência
}

\author{
Pablo Cesar Benetti ${ }^{1}$ \\ Ana Inês Sousa ${ }^{2}$ \\ Maria Helena do Nascimento Souza ${ }^{3}$
}

Resumo: O presente artigo descreve a experiência da Universidade Federal de Rio de Janeiro (UFRJ) no processo de inserção das ações de extensão na grade curricular dos cursos de graduação, tendo em vista a proposta do Plano Nacional de Educação. Ao apresentar uma proposta de ajuste curricular, destacam-se os principais desafios e possibilidades para a inserção dos acadêmicos nas atividades de extensão, de forma a totalizar $10 \%$ da carga horária total do curso de graduação. Para tanto, são descritos os passos adotados pela Pró-Reitoria de Extensão da UFRJ, em conjunto com os coordenadores de extensão e de graduação dos cursos, com a finalidade de adequação dos eixos curriculares. Verifica-se que o processo de inserção da extensão na graduação tem sido uma possibilidade para que docentes, discentes e técnicos administrativos repensem seus conceitos referentes às ações extensionistas e ampliem o interesse pela extensão, possibilitando uma formação mais cidadã e uma maior integração entre a universidade e a sociedade.

Palavras-chave: Extensão Universitária, Currículo, Relações Comunidade-Instituição.

1 Pró-Reitor de Extensão da Universidade Federal do Rio de Janeiro (UFRJ). Professor Associado da Faculdade de Arquitetura e Urbanismo da UFRJ. Endereço: Av. Pedro Calmon, 550 - Prédio da Reitoria - $8^{\circ}$ andar - Salas 815 . Cidade Universitária - Rio de Janeiro RJ - CEP: 21941-901. pablobenetti@pr5.ufrj.br

2 Superintendente Acadêmica da Pró-Reitoria de Extensão da UFRJ. Professor Associado da Escola de Enfermagem Anna Nery da UFRJ. Av. Pedro Calmon, 550 - Prédio da Reitoria - 8ª andar - Salas 815. Cidade Universitária - Rio de Janeiro RJ - CEP: $21941-901$. anaines@pr5.ufrj.br (autora para correspondência)

3 Assessora da Pró-Reitoria de Extensão da UFRJ. Professora Adjunta da Escola de Enfermagem Anna Nery da UFRJ. Av. Pedro Calmon, 550 - Prédio da Reitoria - $8^{\circ}$ andar - Salas 815. Cidade Universitária - Rio de Janeiro RJ - CEP: 21941-901. helenasouza@pr5.ufrj.br 


\title{
Accreditation of university extension in undergraduate courses: experience report
}

\begin{abstract}
This paper describes the experience of the Universidade Federal do Rio de Janeiro (UFRJ) in the process of incorporating extension actions in the curriculum of undergraduate courses, in view of the directives of the Brazilian National Education Plan. A curriculum proposal for its adjustment is presented by highlighting the main challenges and opportunities considered necessary to foster involvement of students in extension activities in order to reach $10 \%$ of the total undergraduate course load. To this end, the steps taken by the dean of extension at UFRJ, together with the extension coordinators and undergraduate courses with the objective of adjusting to the general curriculum directives are described. The inclusion of extension activities in undergraduate courses has represented an opportunity for faculty members, the student body and administrative staff to rethink their concepts and expand interest in university extension programs, and also to enable more civic education actions and a closer integration between the university and society.
\end{abstract}

Keywords: University Extension, Curriculum, Community-Institutional Relations.

Accreditación de la extensión universitária en los cursos de graduación: relato de experiencia

Resumen: Este artículo describe la experiencia de la Universidade Federal do Rio de Janeiro (UFRJ) en el proceso de inserción de acciones de extensión en el plan de estudios de los cursos de graduación, llevando en consideración la propuesta del Plan Nacional de Educación de Brasil. Al presentar una propuesta de ajuste curricular, se destacan los principales desafíos y oportunidades para la inserción de las actividades de extensión, para que alcancen el 10\% de la carga horaria total del curso de graduación. Para este propósito, se describen las medidas adoptadas por la Pro-Rectoria de Extensión de la UFRJ, juntamente con los coordinadores de extensión y de graduación, con el fin de adecuación de los ejes curriculares. Todo indica que el proceso de inserción de la extensión en la graduación ha sido una oportunidad para que los profesores, estudiantes y el personal administrativo hagan un replanteamiento de sus conceptos acerca de las acciones de extensión universitaria, ampliando el interés por ella, lo que permite una formación más cívica y una mayor integración entre la universidad y la sociedad.

Palabras-clave: Educación Permanente, Curriculum, Relaciones Comunidad-Institución.

\section{Introdução}

A extensão universitária é concebida como "um processo interdisciplinar educativo, cultural, científico e político que promove a interação transformadora entre universidade e outros setores da sociedade" (FORPROEX, 2012), mediante o envolvimento de alunos, docentes e técnicos administrativos, do corpo social da Universidade, em ações voltadas para atender as demandas da população.

Para compreender o que são ações de extensão, é necessário pensá-las a partir de suas diretrizes: interação dialógica; interprofissionalidade e interdisciplinaridade; indissociabilidade entre ensino, pesquisa e extensão; impacto na formação do estudante e impacto social (FORPROEX, 2012).

O princípio da interação dialógica orienta que o desenvolvimento de relações entre Universidade e setores sociais devem ser marcadas pelo diálogo e troca de saberes, substituindo o discurso da hegemonia acadêmica pela ideia de aliança com movimentos, setores e organizações sociais. A interdisciplinaridade $e$ interprofissionalidade - implicam na necessidade de considerar de forma integrada os diversos conhecimentos desenvolvidos na universidade nas várias disciplinas e áreas do conhecimento, mediante a construção de alianças intersetoriais, interorganizacionais e interprofissionais. A indissociabilidade ensinopesquisa-extensão - considera que as ações de extensão adquirem maior efetividade se estiverem vinculadas ao processo de formação de pessoas (ensino) e de geração de conhecimento (pesquisa).

Já o impacto na formação do estudante - considera que a extensão possibilita o enriquecimento da experiência discente em termos teóricos e metodológicos e, por isso, deve estar sustentada em iniciativas que viabilizem a flexibilização curricular e a integralização de créditos. Por fim, o princípio do impacto na transformação social - reafirma a Extensão Universitária como o mecanismo pelo qual se estabelece a inter-relação da Universidade com os outros setores da sociedade, com vistas a uma atuação transformadora, voltada para os interesses e necessidades da maioria da população e propiciadora do desenvolvimento social e regional e de aprimoramento das políticas públicas (FORPROEX, 2012). 
A partir destas diretrizes verifica-se que a extensão universitária muda a concepção pedagógica de ensino, introduzindo um novo conceito de sala de aula, com novas metodologias de aprendizagem, que apresentam uma preocupação com a formação cidadã e não apenas técnica, e ampliam o acesso e a democratização do saber. Nesse sentido, o conhecimento que o estudante adquire fora da sala de aula, a partir da interação com a comunidade, contribui para que este adquira uma visão diferenciada do mundo (NUNES; VIEIRA, 2012).

Nesta perspectiva a extensão universitária exerce uma função essencial no ensino superior brasileiro, tanto para o aperfeiçoamento dos discentes, quanto para o processo de formação continuada dos docentes, para que ambos busquem estabelecer uma relação com a sociedade, visando a de troca de saberes, a construção de um pensamento crítico e a melhoria da qualidade de vida da população (FERNANDES et al, 2012).

No Brasil, o princípio da indissociabilidade entre ensino, pesquisa e extensão, foi estabelecido no artigo $n^{\circ} .207$ da Constituição Federal de 1988. Este artigo ressaltou a necessidade de uma formação crítica do estudante ancorada tanto na pesquisa como na atividade de extensão universitária, e a autonomia da Universidade, com a reafirmação do seu papel independente de governos e, ao mesmo tempo, fortemente comprometida com o desenvolvimento nacional (BRASIL, 1988).

Posteriormente, a Lei de Diretrizes e Bases da Educação (Lei Federal no 9.394/96) estabeleceu a flexibilização dos currículos dos cursos de graduação, trazendo uma nova concepção de currículo (BRASIL, 1996). Esta concepção entende a formação como resultado de uma série de atividades e experiências entre as quais a sala de aula é uma delas, sendo absolutamente consciente de que as outras atividades não são menos importantes na formação dos alunos. O pensamento que norteia esta proposta de estrutura curricular é que, para além da formação numa profissão específica, deve ser considerada a formação de cidadãos conscientes de sua responsabilidade social.

Em 2001, o Plano Nacional de Educação 2001-2010 (Lei Federal no 10.172/2001) em sua Meta 23 para a educação superior, indicou a reserva mínima de dez por cento do total de créditos exigidos para a graduação no ensino superior no País, para a atuação dos estudantes em atividades de extensão (BRASIL, 2001). A referida Meta foi reafirmada na Estratégia 12.7 do novo Plano Nacional de Educação (2011-2020), Lei Federal n ${ }^{\circ} 13.005$, que visa "assegurar, no mínimo, $10 \%$ (dez por cento) do total de créditos curriculares exigidos para a graduação em programas e projetos de extensão universitária, orientando sua ação, prioritariamente, para áreas de grande pertinência social” (BRASIL, 2014).

Diante do exposto, o presente artigo objetivou descrever a experiência da Universidade Federal de Rio de Janeiro (UFRJ) no processo de inserção das ações de extensão na grade curricular dos cursos de graduação, tendo em vista o cumprimento da meta do Plano Nacional de Educação.

\section{A trajetória metodológica para a inserção curricular da extensão}

A seguir serão descritos os passos adotados pela PróReitoria de Extensão (PR-5) da Universidade Federal do Rio de Janeiro (UFRJ), com o apoio da Plenária de Coordenadores de Extensão dos Centros e Diretores Adjuntos das Unidades, da Pró-Reitoria de Graduação e dos coordenadores de extensão e de graduação dos cursos, tendo em vista a inserção e creditação das ações extensionistas nos eixos curriculares dos cursos de graduação.

O tema da flexibilização curricular (FORPROEX, 2006) e a preocupação com a integralização das atividades de extensão nos cursos de graduação tem sido temática de discussão nos Congressos de Extensão promovidos pela UFRJ desde o ano 2006.

No período de outubro de 2011 a abril de 2012, a PróReitoria de Extensão (PR-5), com o apoio da Plenária de Coordenadores de Extensão de Centros e Unidades e da Pró-Reitoria de Graduação, realizou uma pesquisa intitulada: "(Re)conhecendo a extensão na UFRJ: Levantamento de atividades de extensão passíveis de receber créditos nos Cursos de Graduação da UFRJ“ (BENETTI et al, 2013).

Este levantamento teve como objetivo avaliar a situação da UFRJ em relação à inclusão dos dez por cento de extensão nos currículos dos cursos de graduação, identificando assim os cursos que já creditavam a extensão em seus respectivos currículos e de que forma ocorria esse processo; além de mapear outras atividades passíveis de serem aproveitadas para concessão de créditos. Para este levantamento, inicialmente, foram realizadas reuniões de sensibilização e mobilização junto aos coordenadores de graduação e de extensão. Posteriormente, todas as unidades preencheram um questionário eletrônico disponível na página eletrônica da PR-5. Para complementar os dados, realizou-se, ainda, um levantamento na Pró-Reitoria de Graduação para identificar as disciplinas obrigatórias, eletivas ou os requisitos curriculares suplementares (RCS) já existentes; e também foram feitas visitas às unidades.

Os resultados desta pesquisa mostraram que, dentre as modalidades de creditação da extensão na UFRJ, encontravam-se: 228 disciplinas ou RCS, 145 programas ou projetos e 234 ações classificadas como outras atividades extensionistas, tais como eventos e cursos de extensão. Tais dados revelaram que, em 2012, nenhum dos currículos dos cursos de graduação da UFRJ apresentava o percentual mínimo de dez por cento de atividades de extensão, conforme o preconizado pelo Plano Nacional de Educação vigente (BRASIL, 2014).

Após a discussão dos resultados deste levantamento com a Plenária de Coordenadores de Extensão (instância criada pela Pró-Reitoria de Extensão que reúne mensalmente os coordenadores de extensão dos Centros e Unidades da UFRJ) e no $9^{\circ}$ Congresso de Extensão da UFRJ, realizado em outubro de 2012, houve a proposta de elaboração de uma minuta de Resolução para 
encaminhamento ao Conselho de Ensino de Graduação (CEG), objetivando regulamentar o registro e a inclusão das ações de extensão nos currículos dos cursos de graduação da UFRJ. Esta Resolução foi aprovada em dezembro de 2012 pela Plenária de Coordenadores de extensão e encaminhada para o CEG em janeiro de 2013. No CEG, foi analisada pela Câmara de Legislação e Normas, sendo aprovada em 05/06/2013 a Resolução CEG No 02/2013 (UFRJ, 2013).

No seu artigo $5^{\circ}$, esta Resolução estabelece que:

A inclusão de atividades de extensão reconhecidas pela UFRJ no histórico escolar dos estudantes dos cursos de graduação se dará por meio de disciplinas ou Requisitos Curriculares já existentes em alguns cursos e/ou pela criação de um conjunto de RCS/EXT - Requisitos Curriculares Suplementares, denominados "Atividades Curriculares de Extensão", com carga horária variável, em formato a ser definido por cada Unidade/Curso no seu respectivo projeto pedagógico, dentro dos balizamentos indicados nesta resolução.

Assim, a inserção das atividades de extensão nos cursos de graduação foi aprovada como obrigatória e com o percentual mínimo de dez por cento, conforme se constata no $\S 1^{\circ}$ do artigo $1^{\circ}$ da Resolução CEG 02/2013 (UFRJ, 2013):

O conjunto de RCS-EXT referido no caput desse artigo deverá ser incluído como atividade obrigatória para todos os cursos de graduação da UFRJ, exceto para os cursos que já atendam ao mínimo de $10 \%$ de sua carga horária indicados como atividades de extensão em seus respectivos currículos.

Esta Resolução foi alterada e complementada pelas Resoluções CEG N ${ }^{\circ} 03$ e 04/2014, ambas publicadas em 04/12/2014 (UFRJ, 2014). A primeira autoriza a criação e inserção nos currículos de graduação de disciplinas de natureza mista. Já a segunda, reitera que:

As atividades de extensão, em suas variadas formas, devem obrigatoriamente fazer parte integrante dos currículos de todos os cursos de graduação, perfazendo um percentual mínimo de $10 \%$ da carga horária total do curso.

Para subsidiar a discussão do conteúdo destas Resoluções junto aos coordenadores das unidades foi elaborado um folder e publicado um Guia com orientações sobre o passo a passo do processo de creditação das atividades de extensão na UFRJ (BENETTI et al, 2015). A seguir foram agendadas reuniões nas Unidades acadêmicas com a participação de coordenadores de extensão e coordenadores de curso de graduação para analisar o currículo de cada curso e identificar como inserir as atividades de extensão, sem aumentar a carga horária total do curso. Para essas reuniões foram convidados também coordenadores de programas e projetos de extensão e docentes membros do Núcleo Docente Estruturante (NDE), que são responsáveis pela discussão sobre os currículos dos cursos.
No período de agosto de 2013 a março de 2015 foram realizadas reuniões, em todas as Unidades acadêmicas da UFRJ, com os coordenadores de extensão, graduação e membros dos Núcleos Docente Estruturante. A UFRJ possui 175 cursos de graduação, sendo que ao incluir as habilitações ou ênfases este total passa para 269 modalidades de cursos.

A Figura 1 apresenta o número de cursos de graduação que foram representados nas reuniões com a Pró-Reitoria de Extensão sobre a creditação das ações de extensão e o daqueles que já realizaram o ajuste curricular para a implementação dos $10 \%$ de extensão na grade curricular dos alunos de graduação até o primeiro semestre de 2015 (13 cursos). Tais cursos são organizados nos seguintes Centros da UFRJ: Pólo Xerém, Campus Macaé, Centro de Ciências Jurídicas e Econômicas (CCJE), Centro de Filosofia e Ciências Humanas $(\mathrm{CFCH})$, Centro de Ciências Matemáticas e da Natureza (CCMN), Centro de Tecnologia (CT), Centro de Letras e Artes (CLA) e Centro de Ciências da Saúde (CCS).

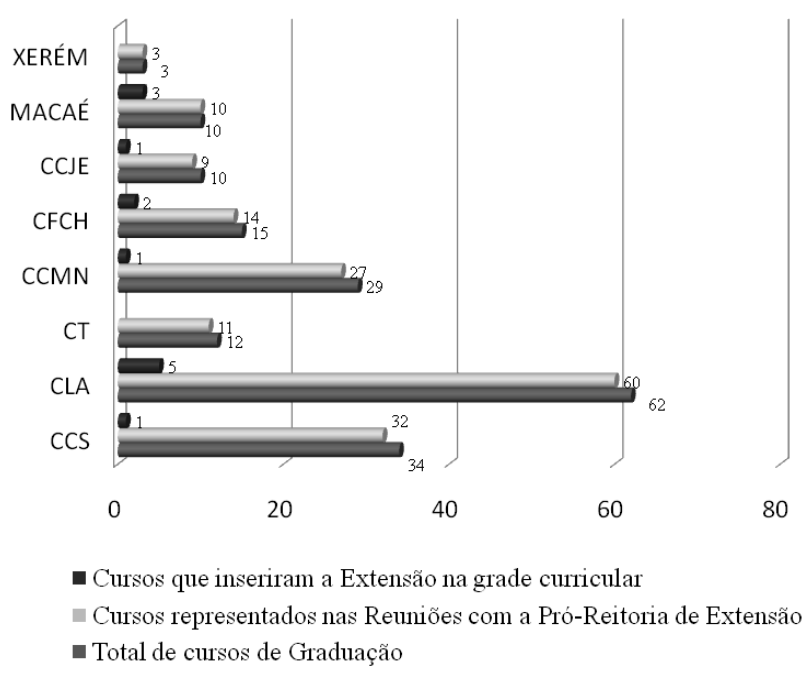

Figura 1. Número de cursos de graduação representados nas reuniões com a Pró-Reitoria de Extensão sobre a creditação das ações de extensão, e que já realizaram o ajuste curricular para a implementação dos $10 \%$ de extensão na grade curricular até o primeiro semestre de 2015. Fonte: os autores.

Acrescentando as habilitações dos cursos de graduação, o número total de modalidades de cursos de graduação passa para 269. Isto significa que quando ocorrerem as discussões nas Unidades para a inserção da extensão em um curso com mais de uma habilitação ou modalidade, o ajuste curricular das respectivas habilitações ou modalidades será facilitado.

As perguntas que surgiram durante as reuniões nas Unidades foram respondidas e disponibilizadas no site da Pró-Reitoria de Extensão, na sessão de perguntas frequentes ${ }^{1}$. Durante as reuniões nas Unidades foram apresentados os passos para o processo de ajuste curricular de creditação da extensão nos cursos de graduação da UFRJ, que consistem em: 
- Alterar ou adequar o Projeto Pedagógico do Curso. Esta ação é importante porque estabelece de maneira clara quando, onde e como serão ofertados os créditos de extensão, permitindo tanto ao aluno ingressante na Universidade, como aos coordenadores de graduação, o controle do cumprimento da Resolução CEG $\mathrm{N}^{\mathrm{o}}$. 02/2013;

- Verificar a carga horária total exigida para a formação dos alunos no curso $^{2}$, calcular a carga horária para extensão equivalente ao percentual de $10 \%$ da carga horária total e identificar se já existem disciplinas ou Requisitos Curriculares Suplementares (RCS) de extensão na grade curricular do seu curso. Caso existam, verificar qual é a carga horária que cada um concede. Além disso, fazer o balanço do curso, ou seja, verificar quantas horas faltam para atingir os dez por cento de extensão;

- Criar o Grupo Extensão na grade curricular do curso. Com o objetivo de facilitar a identificação da extensão no currículo dos cursos, a Pró-Reitoria de Extensão em conjunto com a Pró-Reitoria de Graduação, elaborou uma proposta de criação de Requisitos Curriculares Suplementares (RCS) de Extensão que, organizados no Grupo Extensão contemplam as seguintes atividades: i) Programas/Projetos de Extensão, ii) Cursos de Extensão e iii) Eventos. Para cada atividade podem ser criados mais de um RCS sem pré-requisito, com diferentes cargas horárias e com duração máxima de até dois semestres letivos (Quadro 1).

A Pró-Reitoria de Extensão e a Pró-Reitoria de Graduação elaboraram, ainda, uma proposta de ementas para estes RCS do Grupo Extensão, que está sendo adotada pela maioria dos cursos (Quadro 2).

Quadro 1. Exemplo de Requisitos Curriculares Suplementares (RCS) que contemplam o Grupo Extensão na grade curricular dos cursos de graduação da UFRJ.

\begin{tabular}{|l|l|}
\hline \multicolumn{1}{|c|}{ RCS } & \multicolumn{1}{c|}{ Carga horária } \\
\hline Programas e Projetos I, II, III & $90 \mathrm{~h}, 180 \mathrm{~h}, 180 \mathrm{~h}$ \\
\hline Cursos de Extensão I, II, III & $30 \mathrm{~h}, 45 \mathrm{~h}, 60 \mathrm{~h}$ \\
\hline Eventos de Extensão & $30 \mathrm{~h}, 45 \mathrm{~h}, 60 \mathrm{~h}$ \\
\hline Iniciação à Extensão & $45 \mathrm{~h}$ ou 60h \\
\hline Atividade de Extensão I, II, III & $60 \mathrm{~h}, 90 \mathrm{~h}, 180 \mathrm{~h}$ \\
\hline
\end{tabular}

Fonte: os autores.

Após os ajustes curriculares, os RCS do Grupo Extensão são vinculados aos cursos de graduação, através do sistema informatizado de registro de disciplinas da UFRJ (Sistema Integrado de Gestão Acadêmica - SIGA) e, para identificar que são de Extensão, estes recebem a letra $\mathbf{Z}$ (no quarto dígito do código de cada RCS). Assim, o estudante que se matricular no RCS/EXT cumprirá sua carga horária atuando em alguma atividade de extensão registrada na Pró-Reitoria de Extensão (programa, projeto, curso, evento), sob a orientação do coordenador da ação. Ou seja, todas as ações de extensão passam a ser visíveis pela existência do registro.

Quadro 2. Ementas dos Requisitos Curriculares Suplementares (RCS) que contemplam o Grupo Extensão na grade curricular dos cursos de graduação da UFRJ.

\begin{tabular}{|l|l|}
\hline \multicolumn{1}{|c|}{ RCS } & \multicolumn{1}{|c|}{ Ementa } \\
\hline Programas e Projetos I, II, III & $\begin{array}{l}\text { Atuação em programas/projetos de extensão registrados na Pró-Reitoria de } \\
\text { Extensão da UFRJ, coordenados por docentes do quadro permanente ou técnicos da } \\
\text { carreira de nível superior na UFRJ e com trabalho apresentado em evento com essa } \\
\text { finalidade. }\end{array}$ \\
\hline Cursos de Extensão I, II, III & $\begin{array}{l}\text { Atuação em cursos de extensão registrados na Pró-Reitoria de Extensão da UFRJ, } \\
\text { coordenados por docentes do quadro permanente ou técnicos da carreira de nível } \\
\text { superior na UFRJ, seja na organização ou ministrando aulas. }\end{array}$ \\
\hline Eventos de Extensão I, II, III & $\begin{array}{l}\text { Atuação em eventos registrados na Pró-Reitoria de Extensão da UFRJ, } \\
\text { coordenados por docentes do quadro permanente ou técnicos da carreira de nível } \\
\text { superior na UFRJ, seja na organização ou na realização do evento. }\end{array}$ \\
\hline Atividade de Extensão I, II, III & $\begin{array}{l}\text { Atuação em atividades de extensão registradas na Pró-Reitoria de Extensão da } \\
\text { UFRJ, como programas, projetos, cursos de extensão e eventos, coordenados por } \\
\text { docentes do quadro permanente ou técnicos da carreira de nível superior na UFRJ. } \\
\text { Para eventos, a atuação deverá ser na organização ou na realização dos mesmos. } \\
\text { Para cursos, a atuação deve ser na organização ou ministrando aulas. }\end{array}$ \\
\hline Iniciação à Extensão & $\begin{array}{l}\text { Evolução histórica, construção conceitual, princípios e diretrizes da extensão nas } \\
\text { universidades públicas. Políticas de extensão universitária na UFRJ e no Brasil. } \\
\text { Tipos de ações de extensão, inserção curricular das ações de extensão na UFRJ. } \\
\text { Metodologia aplicável às ações de extensão. Apresentação e aproximação com as } \\
\text { ações de extensão da Unidade e da UFRJ. }\end{array}$ \\
\hline
\end{tabular}


Portanto, na grade curricular do aluno constará o Grupo Extensão e no histórico escolar do mesmo será incluído o nome do projeto, o nome do coordenador e o local de realização da ação extensionista.

Paralelamente à criação do Grupo Extensão, os coordenadores deverão identificar os programas, projetos, cursos de extensão e eventos, que existem na unidade, verificar se estão registrados na Pró-Reitoria de Extensão (PR-5). Se não estiverem, devem aprovar na Unidade e registrar na Pró-Reitoria de Extensão (PR-5). Todas as ações de extensão citadas anteriormente deverão ser aprovadas nos órgãos colegiados das unidades acadêmicas da UFRJ e registradas na plataforma do SIGPROJ (Sistema de Informação e Gestão de Projetos), que constitui um sistema nacional adotado pela Pró-Reitoria de Extensão da UFRJ para cadastro dos programas, projetos, cursos e eventos, de extensão. Para registro no SIGPROJ, o coordenador deve fazer seu cadastro ${ }^{3}$ e selecionar o Edital da UFRJ correspondente ao tipo de ação de extensão a ser registrada - Edital Fluxo Contínuo de Programas e Projetos, Cursos de Extensão ou de Eventos. Após o preenchimento do formulário de registro da atividade, deve "salvar" e "submeter proposta para o julgamento", que será realizado por pareceristas designados pela PróReitoria de Extensão.

Os coordenadores dos cursos deverão divulgar amplamente a nova grade curricular aos alunos matriculados na UFRJ a partir de 2015, bem como as atividades de extensão da Unidade e da UFRJ como um todo, para que estes possam se inscrever, de forma a cumprir o percentual de dez por cento da carga horária total do curso, conforme preconiza a Resolução CEG $\mathrm{N}^{\mathrm{o}}$ 02/2013. No sítio eletrônico da PR-5 é possível encontrar uma descrição sucinta de cada projeto, programa ou curso, divididos por área temática ${ }^{4}$.

Para facilitar a visibilidade e divulgação das ações de extensão (programas, projetos, cursos e eventos) realizadas pelos docentes, discentes e técnicos administrativos da UFRJ e registradas na Pró-Reitoria de Extensão, em 2015 foi criado o Mapa da Extensão da UFRJ $^{5}$. O Mapa da Extensão na UFRJ, criado com a colaboração do laboratório ReAbilitArte do Instituto Tércio Pacitti de Aplicações e Pesquisas Computacionais (NCE/UFRJ), tem a finalidade de facilitar a compreensão dos estudantes no momento de inscrição nos Requisitos Curriculares (RCS) de Extensão e divulgar informações relativas às ações de extensão da UFRJ: programas, projetos, cursos e eventos registrados no sistema SIGPROJ e que podem ser creditadas nos currículos dos cursos de graduação.Utilizou-se o sistema Google Maps para identificar o local de realização da atividade de extensão. Ao acessar uma determinada ação é possível conhecer as seguintes informações: nome e contato do coordenador, unidade de origem na UFRJ, área temática, resumo da ação, público alvo e principal local de realização. Desta forma, o aluno que ingressa em algum curso de graduação da UFRJ terá maior facilidade para se inserir nas ações de extensão e cumprir os $10 \%$ (dez por cento) da carga horária total do curso, preconizados pelo Plano Nacional de Educação.
Além das discussões internas, este tema de Creditação das ações de extensão tem sido aprofundado nos Fóruns de Pró-Reitores das Universidades Brasileiras, nos Congressos ou Seminários de Extensão e nos encontros denominados Rodas de Conversas sobre Creditação da Extensão (promovidos pelas Pró-Reitorias de Extensão das Universidades públicas da região Sudeste).

Neste sentido, a Pró-Reitoria de Extensão tem sido convidada para compartilhar a experiência da UFRJ sobre o processo de inclusão da extensão nos currículos dos cursos de graduação em diversos eventos, como por exemplo: Mesa redonda no $40^{\circ}$ Encontro da Regional Sudeste de Pró-Reitores de Extensão de Instituições Públicas de Educação Superior - FORPROEX (09/10/2012, em Alfenas, Minas Gerais); Mesa redonda no LXI Encontro de Pró-Reitores de Extensão das Instituições Públicas de Ensino Superior da Regional Nordeste (03/10/2013, em Campina Grande, Paraíba); XII Congreso Iberoamericano de Extensión Universitária (19 a 22/11/2013, em Quito, Equador); Mesa redonda promovida pela Universidade Estadual de Feira de Santana (10/04/2013, em Feira de Santana, Bahia); Mesa redonda no $6^{\circ}$ Congresso Brasileiro de Extensão Universitária (19 a 22/05/2014, em Belém, Pará); $32^{\circ}$ Seminário de Extensão Universitária da Região Sul (11/09/2014, em Curitiba, Paraná); 2 $2^{a}$ Roda de Conversa sobre Creditação da Extensão da Região Sudeste (19/09/2014, em São João Del Rei, Minas Gerais); $8^{\circ}$ Fórum de Ensino, Pesquisa, Extensão e Gestão (25/09/2014, na Universidade de Montes Claros; X Semana de Extensão da Universidade Federal Rural do Rio de Janeiro (15/10/2014); Mesa Redonda promovida pela Universidade Federal da Fronteira Sul (27/11/2014, em Chapecó, Santa Catarina); Reunião da Pró-Reitorias de Extensão e Graduação (05/03/2015, na Universidade Estadual Paulista) e; II Seminário Internacional de Extensão Universitária (de 22 a 24/04/2015, na Universidade Federal do Acre).

\section{Considerações finais}

A seguir, sintetizamos os desafios que ora enfrentamos nesse processo de implementação da Estratégia 12.7 do Plano Nacional de Educação, bem como das Resoluções do CEG referentes ao processo de creditação da extensão na UFRJ.

O primeiro desafio consiste em incluir na discussão toda a comunidade acadêmica envolvida com o projeto pedagógico dos cursos (docentes, estudantes e técnicos). Nestas discussões, percebemos a necessidade de esclarecer o significado dos conceitos de programa, projeto, evento e curso de extensão. A conceituação e diretrizes da extensão pactuadas pelo Fórum de PróReitores de Extensão das Instituições Públicas de Educação Superior Brasileiras ainda são pouco conhecidas. Um número significativo de docentes limita o conceito de extensão às ações de divulgação científica, e muitos incluem neste conceito qualquer tipo de evento, ou apenas cursos para o público externo, sem incluir 
nestes a participação dos alunos. A extensão universitária deve envolver obrigatoriamente a participação ativa dos estudantes, a coordenação de docentes ou técnicos administrativos e, sobretudo, as demandas dos demais setores da sociedade. Se algum destes três pilares estiver ausente, não podemos considerar estas ações como extensionistas.

Recentemente, foi aprovada na UFRJ a regulamentação da progressão funcional da carreira docente estabelecendo a obrigatoriedade de pontuação nos três grupos de atividades centrais: ensino, pesquisa, extensão (Resolução CONSUNI $n^{\circ}$. 08/2014), reforçando a proposta de indissociabilidade entre a pesquisa, ensino e extensão, considerando que as três dimensões do saber acadêmico têm igual importância na carreira docente e no processo formativo dos acadêmicos. Além disso, as ações de extensão passaram a ser pontuadas também como um dos critérios de distribuição de vagas docentes pela Comissão Temporária de Alocação de Vagas Docentes (COTAV) da UFRJ. Para a extensão universitária, esta Resolução é um enorme avanço, e acreditamos que deve estimular a aproximação de muitos docentes que hoje não praticam atividades de extensão para esta atividadefim da universidade, o que coloca novos desafios conceituais.

Quando uma atividade é restrita a grupos pequenos, fica mais fácil controlar a pureza conceitual de suas práticas. À medida em que se pretende ampliar o número de participantes, impõe-se a criação de mecanismos de discussão e conceituação compartilhados. Não se constroem conceitos por decreto ou pela mera existência dos mesmos em livros e manuais, é na sua operacionalização que eles são efetivamente assimilados pela maioria dos participantes. Nesta linha de raciocínio, entendemos que um dos maiores desafios colocados pelo movimento que iniciamos com as ações de creditação está justamente na discussão dos conceitos.

O segundo grande desafio consiste em realizar o ajuste curricular para inclusão dos $10 \%$ da extensão sem aumentar a carga horária total dos cursos. Este tem sido o foco das discussões e, durante a elaboração da proposta do ajuste curricular, os coordenadores podem contar com o apoio da equipe da Pró-Reitoria de Extensão e da PróReitoria de Graduação.

Além da inclusão na grade curricular, é necessário que haja ações de extensão disponíveis para inserção de todos os alunos. Assim, um terceiro desafio é ampliar o número de ações, de modo que todos os alunos de graduação tenham a oportunidade de participar e cumprir a carga horária prevista para estas atividades, durante os anos de sua formação. Os representantes das unidades também têm enfatizado a necessidade de infraestrutura, recursos materiais e de pessoal de apoio, para a efetivação das ações extensionistas.

A fim de que os alunos possam conhecer quais as possibilidades de ações de extensão que seu curso ou que outros cursos e Unidades da UFRJ oferecem, é necessária a criação de mecanismos de divulgação de todas as atividades em desenvolvimento. Portanto, neste processo de creditação das atividades de extensão, faz-se necessário que as Universidades formulem uma política institucional de forma participativa, valorizem a contribuição de professores, alunos e técnicos na extensão, e utilizem um sistema único de registro das ações de extensão, de forma que facilite a visibilidade e o contato dos alunos com os coordenadores das ações.

Certos de que há um longo caminho a percorrer, estamos enfrentando os desafios necessários e acreditamos que a implementação da creditação representa um momento importante para a consolidação da extensão universitária no âmbito das Instituições Públicas de Educação Superior Brasileiras.

Diante do exposto, verifica-se que o processo de creditação curricular da extensão nos cursos de graduação da UFRJ tem sido uma possibilidade para que docentes, discentes e técnicos administrativos repensem seus conceitos referentes às ações extensionistas e ampliem o interesse pela extensão, possibilitando uma formação mais cidadã e uma maior integração entre a universidade e os demais setores sociedade.

\section{Notas}

1 Disponível em: http://www.pr5.ufrj.br/index.php/ component/content/article?id=842.

${ }^{2}$ Consultar a grade curricular presente na página da PróReitoria de Graduação, disponível em: http://www.pr1.ufrj.br.

3 O coordenador da ação deve acessar o site: http://sigproj1.mec.gov.br/.

${ }^{4}$ http://www.pr5.ufrj.br/

${ }^{5}$ https://www.google.com/maps/d/viewer?mid=zfwa7dm I7WFM.kFUe6vDh0k6U

\section{Referências}

BENETTI, P.C.; SOUSA, A.I.; SOUZA, M.H.N. Inscripción de créditos en los cursos de graduación de la Universidad Federal de Rio de Janeiro. In: XII Congresso Iberoamericano de extensión universitária. Quito. Anais... Quito, Equador, 2013.

BENETTI, P.C.; SOUSA, A.I.; SOUZA,M.H.N. Guia da Creditação da Extensão da UFRJ. Rio de Janeiro: UFRJ/PróReitoria de Extensão, 2015.

BRASIL. Constituição da República Federativa do Brasil. Brasília: Senado, 1988.

BRASIL. Lei $\mathrm{n}^{\circ} 10.172$, de 9 de janeiro de 2001. Aprova o Plano Nacional de Educação-PNE e dá outras providências. Brasília: 2001. Disponível em: http://www.planalto.gov.br/ccivil_03/leis/leis_2001/110172.htm . Acesso em: 13 ago. 2014.

BRASIL. Lei $\mathrm{n}^{\circ}$. 9394/96, de 20 de dezembro de 1996. Estabelece as Diretrizes e Bases da Educação Nacional. Brasília, 1996. Diário Oficial da União, n. 248, p. 833- 841, 1996.

BRASIL. Lei $\mathrm{n}^{\circ}$ 13.005, de junho de 2014. Aprova o Plano Nacional de Educação - PNE e dá outras providências. Diário 
Oficial da União, 26 de junho de 2014. Edição extra, p. 1-8, 2014.

FERNANDES, M.C; SILVA, L.M.S; MACHADO, A.L.G; MOREIRA, T.M.M. Universidade e a extensão universitária: a visão dos moradores das comunidades circunvizinhas. Educação em Revista, vol. 28, n. 4, p. 169-19, 2012.

FÓRUM DE PRÓ-REITORES DE EXTENSÃO DAS INSTITUIÇÕES PÚBLICAS DE EDUCAÇÃO SUPERIOR BRASILEIRAS (FORPROEX). Política Nacional de Extensão Universitária. Porto Alegre: UFRGS/Pró-Reitoria de Extensão, 2012.

FÓRUM DE PRÓ-REITORES DE EXTENSÃO DAS UNIVERSIDADES PÚBLICAS BRASILEIRAS. Indissociabilidade Ensino-Pesquisa-Extensão e a Flexibilização Curricular: uma visão da extensão. Porto Alegre: UFRGS; Brasília: MEC/SESU, 2006. (Coleção Extensão Universitária; v.4).

NUNES, R.S.; VIEIRA, L.A. Contribuição da extensão universitária para a autonomia do estudante. Em Extensão, vol. 11, n. 2, p.118-125, 2012.

UNIVERSIDADE FEDERAL DO RIO DE JANEIRO (UFRJ), Conselho de Ensino de Graduação. Resolução CEG N ${ }^{\circ}$ 02/2013. Regulamenta o registro e a inclusão das atividades de extensão nos currículos dos cursos de graduação da UFRJ Rio de Janeiro, 2013. Disponível em http://www.pr5.ufrj.br/images/stories/documentos/CEG2013_0 2.pdf. Acesso em: 01 jul. 2014.

UNIVERSIDADE FEDERAL DO RIO DE JANEIRO (UFRJ), Conselho de Ensino de Graduação. Resolução CEG N ${ }^{\circ}$ 04/2014. Altera e Complementa a Resolução CEG 02/2013 Rio de Janeiro, 2014. Disponível em http://www.pr5.ufrj.br/images/stories/documentos/CEG2014_0 4.pdf. Acesso em: $01 \mathrm{dez} .2014$.

UNIVERSIDADE FEDERAL DO RIO DE JANEIRO (UFRJ), Conselho Universitário. Resolução CONSUNI N ${ }^{\circ}$ 08/2014. Estabelece normas e critérios para o desenvolvimento na Carreira de Magistério Federal da UFRJ. Rio de Janeiro, 2014. Disponível

em: http://www.consuni.ufrj.br/images/Resolucoes/Resolu\%C3\%A 7\%C3\%A3o n\%C2\%BA 08 de 2014.pdf Acesso em: 14 mar. 2015.

Como citar este artigo:

BENETTI, P. C.; SOUSA, A. I.; SOUZA, M. H. N. Creditação da extensão universitária nos cursos de graduação: relato de experiência. Revista Brasileira de Extensão Universitária. v. 6 , n. 1, p. 25-32, 2015. Disponível em: <https://periodicos.uffs.edu.br/index.php/RBEU/article/view/19 $\underline{51 / \mathrm{pdf}}>$ 